\title{
Novel temperature-controlled RFA probe for treatment of blocked metal biliary stents in patients with pancreaticobiliary cancers: initial experience
}

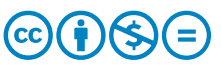

\author{
Authors \\ Manu K. Nayar, Kofi W. Oppong, Noor L.H. Bekkali, John S. Leeds
}

Institution

HPB Unit, Freeman Hospital, Newcastle upon Tyne, United Kingdom

submitted 7.8.2017

accepted after revision 19.1.2018

Bibliography

DOI https://doi.org/10.1055/s-0044-102097 |

Endoscopy International Open 2018; 06: E513-E517

(c) Georg Thieme Verlag KG Stuttgart · New York

ISSN 2364-3722

Corresponding author

Dr. Manu K Nayar, Consultant Pancreatobiliary Physician, Level 6, Freeman Hospital, Newcastle upon Tyne, UK

Fax: +00-44-1912231249

Manu.Nayar@nuth.nhs.uk

\section{ABSTRACT}

Background and study aims Radiofrequency ablation (RFA) is used to treat blocked biliary stents in patients with pancreaticobiliary $(\mathrm{PB})$ tumors with varying results. We re- port our experience with a novel temperature-controlled probe for treatment of blocked metal stents.

Patients and methods Patients with histologically proven PB cancers and a blocked biliary stents were treated using ELRATM electrode (Taewoong Medical) under fluoroscopic guidance. Demographics, clinical outcome, stricture diameter improvements, complications and mortality at 30 days were prospectively recorded.

Results Nine procedures were performed on seven patients (4 male, 3 female); mean age 65.33 (range 56-82 years). Mean stricture diameter prior to RFA was $1.13 \mathrm{~mm}$ $(\mathrm{SD} \pm 0.54)$ and $4.42 \mathrm{~mm}(\mathrm{SD} \pm 1.54)$ following RFA $(P<$ $0.0001)$. Five of seven patients $(71 \%)$ required additional stents to ensure optimal drainage. There were no procedure-related complications. Mean follow-up was 193.55 days (range $31-540$ ) and three of nine patients (33\%) died due to terminal cancer.

Conclusion These are the first reported data on use of a temperature-controlled RFA catheter in humans to treat blocked metal biliary stents. The device is safe but further randomized trials are required to establish the efficacy and survival benefits of this probe.

\section{Introduction}

Survival is limited in patients with PB tumors and continues to be poor inspite of chemotherapy and/or radiotherapy [1,2]. Palliative endoscopic biliary stenting to relieve obstruction and maintain biliary flow is the mainstay intervention in management of these patients. However stents can become blocked resulting in repeated admissions and procedure-related morbidity and mortality [3]. Efforts have been ongoing to develop adjunctive interventions to improve the period of patency of biliary stents including photodynamic therapy (PDT), intraductal radiotherapy, and radiofrequency ablation (RFA) [4]. RFA has emerged as a promising modality in the last few years. RFA may reduce tumor volume prior to biliary stenting or can be used to ablate ingrowth of tumor in previously placed stents [5]. Although much of the data has arisen from retrospective analysis and primarily in patients with cholangiocarcinoma, the safety profile appears acceptable. Much of the previous data has been concerned with primary RFA (delivered to the tumor prior to stent insertion) and several studies have shown that this has been associated with improved survival [5-8]. With respect to treatment of tumor ingrowth and subsequent occlusion of biliary metal stents, there are several case series demonstrating technical feasibility and safety of RFA in this setting (secondary RFA). Only one study has examined endobiliary RFA purely in patients with occluded metal stents and matched to controls in which plastic stents were inserted across the occluded metal stent. That study showed improved stent patency at 90 days and longer overall stent patency but did not comment on survival between the two groups [9]. To our knowledge secondary RFA has been shown to improve stent patency and time to further intervention but overall survival has not been well studied. 


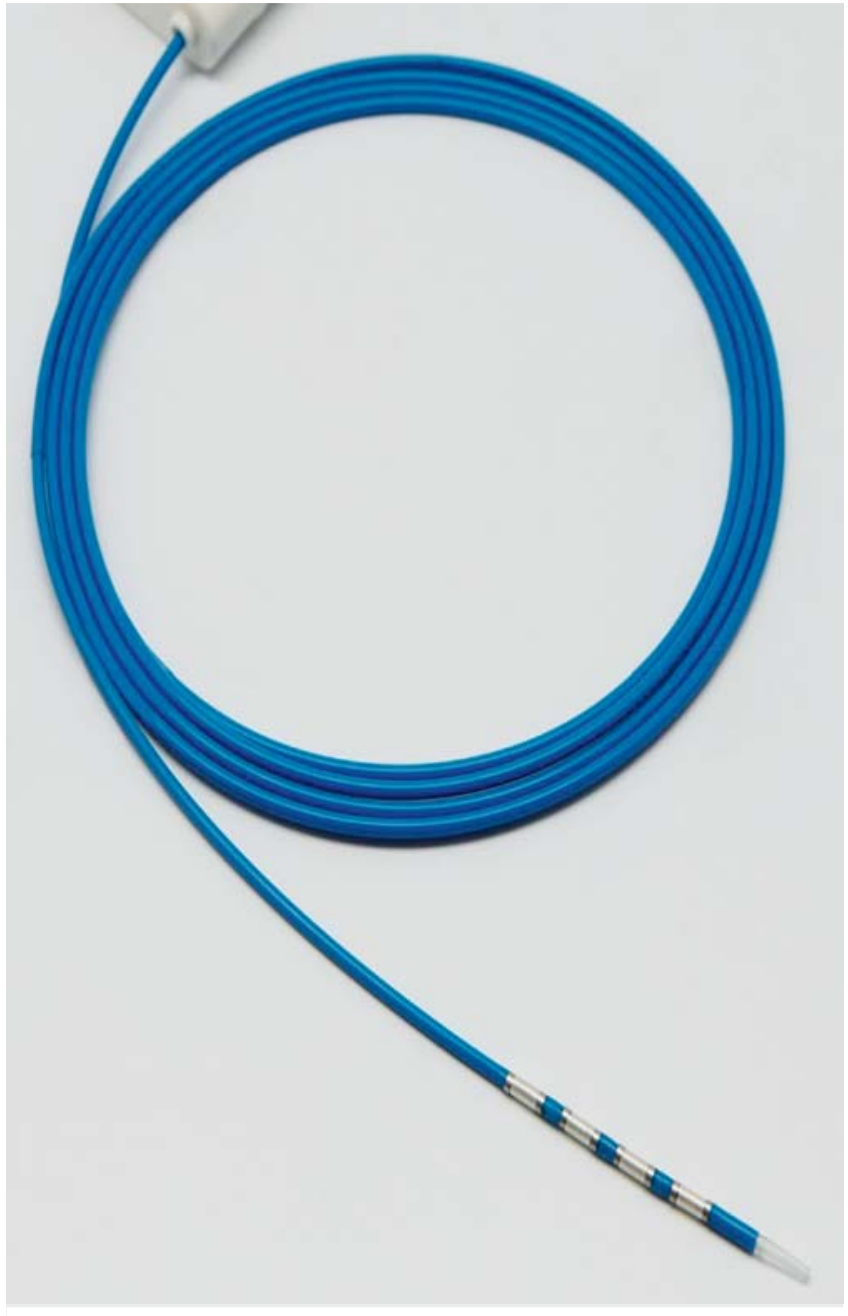

- Fig. 1 ELRA TM catheter - $18 \mathrm{~mm}$.

In addition, most of the studies have been performed using the commonly used probe available in the market i.e. EndoHPB (EMcision, Hitchin Herts, UK) with variable data on safety and efficacy. A new probe has been introduced which controls the temperature at the interface tissue electrode. This probe comes in two sizes and comprises four electrodes rather than two. The generator is set to 10 watts but the current flow is determined by the temperature measured at the tip of the probe. In animal studies this has been shown to limit the charring process, leading to longer-lasting current flow and more effective tissue ablation [10]. We describe the first UK experience with use of this endoluminal RFA probe in a series of patients for treatment of blocked metal biliary stents.

\section{Patients and methods}

Inclusion criteria were presenting signs and symptoms of a blocked metal biliary stent in patients with histologically proven malignant biliary stricture. This study was done between July 2016 and April 2017. As this was the first RFA probe used in the unit, the patients were considered for RFA treatment after careful discussion among the pancreatobiliary multidisciplinary

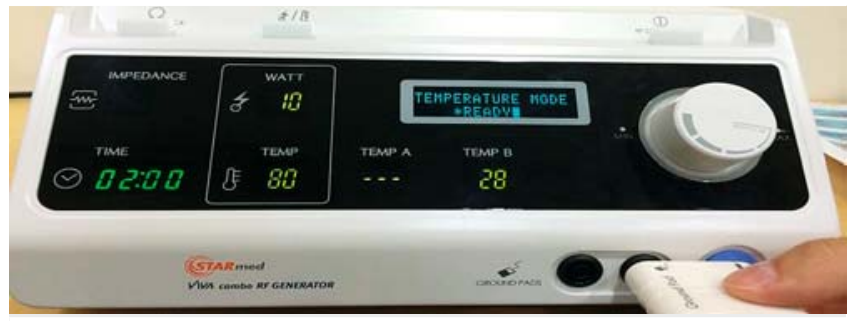

Fig. 2 VIVO generator.

team. Exclusion criteria were lack of fitness for any form of endoscopic intervention or inaccessibility of a biliary stent (e.g. duodenal obstruction) precluding endoscopic retrograde cholangiopancreatography (ERCP). Demographic and clinical details were collected in a prospectively maintained database and included age, sex, type and site of tumor, bilirubin before and after the procedure, stricture diameter before and after RFA, complications at 24 hours and 30-day mortality. Stricture diameter was measured by study of the cholangiographic images pre- and post-treatment by JSL \& MKN. Approval was obtained from the New Interventional Procedure Committee of the Newcastle upon Tyne Hospitals NHS foundation trust prior to clinical use of the new probe.

\section{RFA technique}

The RFA probe used in the patients was the ELRA ${ }^{\mathrm{TM}}$ (EndoLuminal Radiofrequency Ablation) electrode (Taewoong Medical, South Korea; Fig. 1). The length of the probe is $18 \mathrm{~mm}$, diameter $7 \mathrm{Fr}$, ablation depth $4 \mathrm{~mm}$ and it has multiple bipolar electrodes which provide linear ablation and therefore there is no need for ground pads. The VIVA (Taewoong Medical, South Korea; Fig. 2) combo generator is versatile and the settings include power (range 0 watts to 200 watts), and temperature (range $5^{\circ} \mathrm{C}$ to $95^{\circ} \mathrm{C}$ ) and time (range 10 seconds to 10 minutes).

The target area was identified during ERCP ( $\triangleright$ Fig.3a). The VIVA combo-generator ( $\triangleright$ Fig. 2) was set to 2-minute duration, maximum temperature of $80^{\circ} \mathrm{C}$ and a power of 10 watts and then connected to the 18-mm ELRA catheter ( $\triangleright$ Fig. 1 ). The "Start" button of the VIVA combo-generator was pressed and the current was delivered. The settings are similar to the commonly used probe but the potential advantage of this probe is that the RFA with the current settings will not be delivered unless the probe is in contact with the malignant tissue ( $\triangleright$ Fig.3b). This feature is unique to this probe and potentially safe for the patient as compared to the commonly used probes because with the latter it is impossible to know if the current is being delivered to the malignant tissue alone. Once the 2 minutes were over; the ELRA probe was removed and the stricture reassessed with a repeat cholangiogram ( $\nabla$ Fig. $3 \mathbf{c}$ ). The procedure was repeated if there was partial resolution of the stricture or the stricture was longer than $2 \mathrm{~cm}$. At the end of the procedure a biliary stent (metal or plastic) was inserted through the indwelling metal stent. The decision to restent in the latter group was to prevent any further blockage and therefore hospital readmission in this complex group of patients. Re-stenting was common in previous studies and generally performed to ensure 

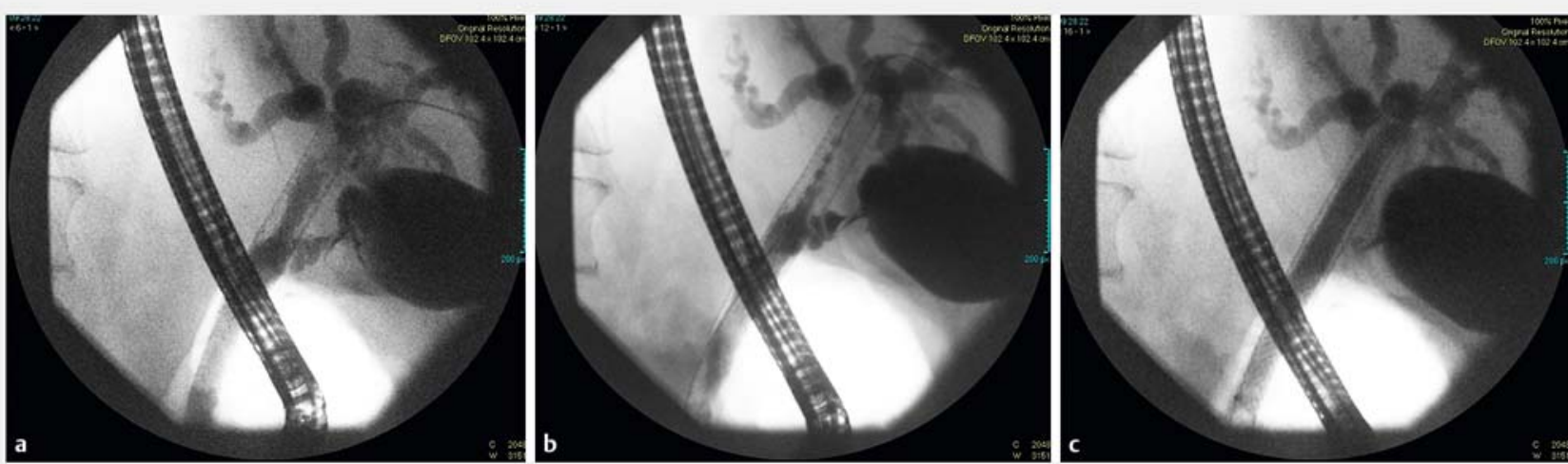

- Fig. 3 Cholangiogram of patients treated with RFA. a Cholangiogram prior to RFA treatment. b Cholangiogram showing the RFA probe across the stricture. c Cholangiogram of a patient following successful RFA treatment; successful stricture resolution.

complete biliary drainage. Following RFA there is a theoretical risk of necrotic material occluding the duct and so restenting could potentially negate the risk.

The patients were then monitored for any complications before discharge. They were followed up for 7 days after the procedure for immediate complications and the 30-day mortality rate was recorded. All patients have been followed up to date.

\section{Results}

Seven patients ( 4 male; 3 female) had nine procedures performed during the study period. Demographic and clinical details are depicted in $>$ Table 1 . Two patients were admitted with cholangitis due to blocked stents and the other five patients had worsening obstructive liver function tests prior to RFA. Five of seven patients $(71 \%)$ required the standard protocol for ablative therapy (i.e., 2 minutes at 10 watts and $80^{\circ} \mathrm{C}$. Two patients required the treatment to be repeated, one because response was suboptimal and the other because of a stricture $>2 \mathrm{~cm}$. Additional biliary stents were inserted in five of seven patients (71\%) ( 2 plastic \& 3 self-expandable metal stents) to maintain biliary drainage. The two patients who did not have additional stents inserted did not require repeat procedures. Antibiotics were given pre- and post-procedure. Mean stricture diameter prior to RFA was $1.13 \mathrm{~mm}$ (standard deviation 0.54 ) and $4.42 \mathrm{~mm}$ (standard deviation 1.54) following RFA $(P<0.0001)$.

There were no immediate procedure-related complications. One patient with colorectal metastasis required three procedures due to recurrent blockages. These procedures were at 1 week and 6 weeks after the first procedure. That patient died 8 weeks after the first procedure due to end-stage malignant disease. The other patient had a complex hilar stricture which required stenting of the contralateral duct after the first procedure. The mean follow-up period was 193.55 days (range 31 to 540 days). Three of nine patients (33\%) died due to end-stage malignant disease at 31, 34 and 52 days, respectively.

- Table 1 Demographics and clinical details.

\begin{tabular}{|c|c|c|c|c|c|c|c|c|}
\hline Age & Sex & Type of tumor & $\begin{array}{l}\text { Stricture } \\
\text { length }\end{array}$ & $\begin{array}{l}\text { Stricture di- } \\
\text { ameter pre- } \\
\text { RFA (mm) }\end{array}$ & $\begin{array}{l}\text { Stricture di- } \\
\text { ameter post- } \\
\text { RFA (mm) }\end{array}$ & $\begin{array}{l}\text { Bilirubin } \\
\text { pre-proce- } \\
\text { dure }\end{array}$ & $\begin{array}{l}\text { Bilirubin } \\
\text { post-proce- } \\
\text { dure }\end{array}$ & $\begin{array}{l}\text { Out- } \\
\text { come }\end{array}$ \\
\hline 74 & $\mathrm{~F}$ & Gallbladder cancer & $15 \mathrm{~mm}$ & 1.55 & 3.79 & 129 & 43 & Alive \\
\hline 69 & $\mathrm{~F}$ & Pancreatic cancer & $25 \mathrm{~mm}$ & 1.2 & 4.48 & 4 & 6 & Alive \\
\hline 63 & $\mathrm{M}$ & Hilar cholangiocarcinoma & $20 \mathrm{~mm}$ & 1.29 & 6.26 & 231 & 265 & Died \\
\hline 62 & $\mathrm{M}$ & Distal cholangiocarcinoma & $20 \mathrm{~mm}$ & 1.33 & 3.57 & 66 & 18 & Died \\
\hline 70 & $\mathrm{~F}$ & Pancreatic cancer & $20 \mathrm{~mm}$ & 2.04 & 6.15 & 114 & 81 & Alive \\
\hline 82 & M & Hilar cholangiocarcinoma & $15 \mathrm{~mm}$ & 0.30 & 2.34 & 90 & 86 & Alive \\
\hline 56 & $\mathrm{M}$ & Colorectal cancer metastasis & $15 \mathrm{~mm}$ & 1.28 & 5.21 & 208 & 173 & Died \\
\hline
\end{tabular}




\section{Discussion}

Our first experience using this new temperature-controlled RFA probe showed successful biliary metal stent occlusion treatment with no procedure-related complications. These data are promising especially since $>50 \%$ of stents are occluded within 6 months [1-3].

Over the past few decades various thermal ablative therapies have been used including PDT \& RFA to prolong stent patency and improve survival. Data are conflicting on survival following RFA with some studies suggesting improved survival while others focus on prolonged stent patency in the absence of survival [4-6].

RFA creates an electrical circuit by using an alternating current which causes protein denaturation and coagulative necrosis. Because of the poor electrical conductivity of tissues, the closest areas to the electrode experience the highest current and temperature, whereas tissues farther away are heated by thermal conduction (i. e., in these regions, the heat may not be sufficiently high to cause necrosis) [11-13]. Therefore, a key limitation is the extent of coagulation produced by RFA, which is often insufficient to cover the tumor volume. During the coagulation induced by RFA, tissue may become dehydrated and charred. As a result, the current stops, leading to a rise in impedance, which limits the volume of tissue successfully ablated. One of the ways to get around this is by delivering pulsed RFA $[14,15]$.

Although RFA has an acceptable safety profile, complications are not uncommon and it is associated with a low rate of procedure-related mortality. Reported complications include post-procedure infections, abdominal pain, pancreatitis and serious but rare issues such as bile duct perforation, liver infarction, and hemobilia [15].

The commonly used probe in routine clinical practice is the Habib EndoHPB. Advantages include that it can be used with a range of commonly available generators and it allows partial destruction of the tumor prior to stent insertion and also to clear obstructed metal stents $[9,15,16]$. However, there are potential drawbacks. While applying RFA under fluoroscopic control, it is difficult to predict for certain if the entire current is being delivered. It is not clear if adequate temperature and wattage is being applied to the malignant tissue as the energy settings are preset. One of the reasons for this could be that the energy settings have been extrapolated from either in vivo animal model or ex vivo human studies without considering delayed necrosis and heat-sink effects in vivo [17]. This may also result in complications due to inadvertent high temperatures, charring of tissue and shorter current flow, leading to suboptimal response. To circumvent some of these problems, a new electrode has been introduced. The unique feature of the ELRA probe is the temperature control feature, which results in safe ablation causing least damage to blood vessels and prevents tissue charring [10].

Though not a comparative study this is first human study to report on use of this novel temperature-controlled probe for treatment of blocked metal stents in malignant biliary strictures. We did not have any immediate procedure-related com- plications and the probe is technically easy to deploy endoscopically into the biliary tree. There was a wide range of pathology including gallbladder cancer, cholangiocarcinoma, colorectal liver metastasis and pancreatic cancer. We hypothesize that the patient who died 8 weeks after the first procedure had a rapidly growing and aggressive tumor that resulted in recurrent stent blockages.

One of the advantages of using this device is the ease of assembly. In addition, the generator only delivered current when there was good tissue contact with the probe. If that was not the case, the impedance rose steeply and the current was cut off. The probe was then repositioned thus ensuring adequate treatment. It is unclear from literature what happens in this circumstances with the more frequently used probe. Furthermore, there was a statistically significant improvement in stricture diameter following delivery of RFA. However, in the absence of a comparative group as in published literature using the commonly used probe [14-16], it is difficult to draw conclusions on the efficacy of this new RFA probe. Furthermore, the survival benefits reported in these studies are based on primary RFA with the commonly used probe.

Long-term follow-up and survival data are not available as this is a new device and currently RCTs are being considered. This study reflects the poor prognosis of the patients being treated and therefore it is crucial to try and minimize risk as much as possible.

\section{Conclusion}

In conclusion, this novel temperature-controlled endoluminal radiofrequency ablation probe seems to be safe and effective in ablating malignant tissue ingrowth in blocked metal biliary stents (secondary RFA). However, larger randomized controlled studies using this probe are required to establish survival benefit and efficacy.

\section{Competing interests}

None

References

[1] Rizvi S, Gores G]. Pathogenesis, diagnosis, and management of cholangiocarcinoma. Gastroenterology 2013; 145: 1215-1229

[2] Martin R 2nd. Management of locally advanced pancreatic cancer. Surg Clin North Am 2016; 96: 1371 - 1389

[3] O'Brien S, Hatfield AR, Craig PI et al. Three year follow up of self-expanding metal stents in the endoscopic palliation of long-term survivors with malignant biliary obstruction. Gut 1995; 36: 618-621

[4] Strand DS, Cosgrove ND, Patrie JT et al. ERCP-directed radiofrequency ablation and photodynamic therapy are associated with comparable survival in the treatment of unresectable cholangiocarcinoma. Gastrointest Endosc 2014; 80: $794-804$

[5] Kallis Y, Phillips N, Steel A et al. Analysis of endoscopic radiofrequency ablation of biliary malignant strictures in pancreatic cancer suggests potential survival benefit. Dig Dis Sci 2015; 60: 3449-3455 
[6] Sharaiha RZ, Natov N, Glockenberg KS et al. Comparison of metal stenting with radiofrequency ablation versus stenting alone for treating malignant biliary strictures: is there an added benefit? Dig Dis Sci 2014; 59: 3099-3102

[7] Sharaiha RZ, Sethi A, Weaver KR et al. Impact of radiofrequency ablation on malignant biliary strictures: results of a collaborative registry. Dig Dis Sci 2015; 60: 2164 - 2169

[8] Dutta AK, Basavaraju U, Sales L et al. Radiofrequency ablation for management of malignant biliary obstruction: a single-center experience and review of the literature. Expert Rev Gastroenterol Hepatol 2017; 7: 1-6

[9] Kadayifci A, Atar M, Forcione DG et al. Radiofrequency ablation for the management of occluded biliary metal stents. Endoscopy 2016; 48: $1096-1101$

[10] Cho JH, Lee KH, Kim JM et al. Safety and Efficacy of a novel endobiliary radiofrequency ablation catheter $\left(\right.$ ELRA $\left.^{\circledR}\right)$ in a swine model. Gastrointest Endosc 2015; 81: AB350

[11] Alvarez-Sánchez MV, Napoléon B. Review of endoscopic radiofrequency in biliopancreatic tumours with emphasis on clinical benefits, controversies and safety. World J Gastroenterol 2016; 22: 8257-8270
[12] Knavel EM, Brace CL. Tumor ablation: common modalities and general practices. Tech Vasc Interv Radiol 2013; 16: $192-200$

[13] Goldberg SN, Gazelle GS. Radiofrequency tissue ablation: physical principles and techniques for increasing coagulation necrosis. Hepatogastroenterology 2001; 48: 359-367

[14] Shah DR, Green S, Elliot A et al. Current oncologic applications of radiofrequency ablation therapies. World J Gastrointest Oncol 2013; 5: $71-80$

[15] Rhim H, Dodd GD, Chintapalli KN et al. Radiofrequency thermal ablation of abdominal tumors: lessons learned from complications. Radiographics 2004; 24: 41 - 52

[16] Kallis Y, Phillips N, Steel A et al. Analysis of Endoscopic Radiofrequency Ablation of Biliary Malignant Strictures in Pancreatic Cancer Suggests Potential Survival Benefit. Dig Dis Sci 2015; 60: 3449- 3455

[17] Roque J, Ho SH, Reddy N et al. Endoscopic ablation therapy for biliopancreatic malignancies. Clin Endosc 2015; 48: 15-19 